\title{
¿Contribuyen las prácticas agroecológicas a la sustentabilidad de la agricultura familiar de montaña? El caso de Curarrehue, región de la Araucanía, Chile*
}

Nicolás Ricardo Fuentes Acuña**

Carla Marchant***

doi:I0.III44/Javeriana.cdri3-78.cpas

Recibido: 2016-03-29 Aprobado: 2016-12-06 Disponible en línea: 2016-I2-20

Cómo citar este artículo: Fuentes, N. y Marchant, C. (2016). ¿Contribuyen las prácticas agroecológicas a la sustentabilidad de la agricultura familiar de montaña? El caso de Curarrehue, región de la Araucanía, Chile. Cuadernos de Desarrollo Rural, I3(78), 35-66. https://doi.org/10.III44/Javeriana.cdri3-78.cpas

* Artículo de investigación. Este artículo es un resultado del proyecto Fondecyt III40493 de Conicyt, Chile. ** Magíster en Desarrollo Rural, Universidad Austral de Chile, asistente de investigación proyecto Fondecyt. Correo electrónico: mv.nicolasfuentes@gmail.com. Orcid: orcid.org/0000-0001-5376-1098

*** PhD. Profesora en la Universidad Austral de Chile. Académica e investigadora del Instituto de Ciencias Ambientales y Evolutivas. Correo electrónico: carla.@gmail.com. Orcid: orcid.org/0000-0002-4040-8372 


\title{
Resumen
}

La sustentabilidad de la agricultura familiar ha cobrado interés en el actual escenario de cambio ambiental global. En dicho contexto, los sistemas agrícolas de montaña son unos de los temas menos estudiados, a pesar de que permiten un manejo predial a partir del que se mantienen múltiples prácticas tradicionales. La investigación analiza mediante la metodología Mesmis, el grado de sustentabilidad de predios de agricultura familiar, de acuerdo con un enfoque agroecológico y convencional, con el fin de visibilizar el aporte de la agricultura familiar al enfoque agroecológico que se asocia con la sustentabilidad predial en territorios de montaña, en particular en el caso de Curarrehue, en la Araucanía Andina Chilena. Los resultados muestran que la utilización de prácticas agroecológicas, que se basan en los conocimientos locales, son mecanismos que permiten un mejor desempeño de las unidades familiares en los ámbitos ambiental, económico y social.

\section{Palabras clave:}

agricultura familiar; prácticas agroecológicas; sustentabilidad; Mesmis; Araucanía Andina Lacustre

\section{Do Agro-ecological Practices Contribute to Mountain Family Farming Sustainability? The Curarrehue Case, Araucania Region, Chile}

\begin{abstract}
The sustainability of family agriculture has gained interest in the current scenario of global environmental change. In this context, mountain farming systems are one of the least studied subjects, despite the fact that they allow for land management from which multiple traditional practices are maintained. This research analyzes, through the Mesmis methodology, the sustainability degree of family agriculture farms according to an agro-ecological and conventional approach. The purpose is to bring visibility to the contributions of family agriculture to the agro-ecological approach associated with land sustainability in mountain territories, particularly in the case of Curarrehue, in the Chilean Andean Araucania region. The results show that the use of agro-ecological practices, which are based on local knowledge, are mechanisms that allow for a better performance of family units in the environmental, economic, and social spheres.
\end{abstract}

Keywords:

family agriculture; agro-ecological practices; sustainability; Mesmis; Andean lake Araucania 


\section{Introducción}

Los sistemas agrícolas de montaña se caracterizan por su diversidad biológica (Singh, 20I4). Además, son considerados por Kohler y Romeo (2013) como formas de agricultura familiar condicionadas principalmente por la escasez de tierras cultivables y por las dificultades de acceso a tales territorios. Al igual que otros sistemas agrícolas, estos nichos han sido intervenidos por la Revolución Verde que, a través de sus prácticas, ha tenido una serie de efectos negativos en la agricultura, que son evidentes dadas la dependencia de tecnología e insumos externos; la pérdida de variedades genéticas tradicionales, y el desplazamiento a territorios menos productivos (Martínez y Rosset, 20I2).

En el actual contexto de cambio ambiental global (Montaña, 2013), el cual supone nuevos escenarios climáticos y mayores presiones socioeconómicas para los habitantes de las tierras altas (Borsdorf et al.,20I4), la manutención de la agricultura familiar de montaña se transforma en un desafío (Beck, 2013). Se añaden a estas dificultades otros factores biofísicos como el incremento generalizado de las temperaturas y el aumento en la frecuencia de eventos extremos (sequías e inundaciones) en áreas montañosas (Beniston, 2003; IPCC, 2007), al igual que otros fenómenos de origen antrópico, tales como la degradación de suelos por deforestación (Marchant y Sánchez, 20II); la habilitación de tierras para proyectos urbanos (Vargas, Castro y Ziadat, 2015), y el éxodo rural: materias que son relevantes para el futuro de esta actividad (Ruiz y Delgado, 2008).

Sin embargo, a pesar de los efectos negativos que la Revolución Verde tuvo en la agricultura familiar y en escenarios de cambio global cada vez más complejos -efectos que se vislumbran en estas áreas- la agricultura de montaña ha logrado subsistir manteniendo prácticas ancestrales que corresponden a enfoques agroecológicos (Prieto, 2002). Al respecto, Altieri y Toledo (20II) señalan que el enfoque agroecológico ha permitido generar una agricultura sustentable debido a la baja dependencia de insumos externos y a la mitigación de los efectos ocasionados por la Revolución Verde en el medio ambiente: circunstancias que tienen efectos en la conservación de los suelos, el agua y la biodiversidad, y que acarrean la supresión de agro-tóxicos y transgénicos.

Bajo esta premisa, las prácticas agroecológicas se constituyen como alternativas que contribuyen a la sustentabilidad de los agroecosistemas y al manejo de los recursos naturales en zonas rurales (Gutiérrez, Aguilera y González, 2008). Asimismo, representan alternativas ante los mecanismos extensionistas convencionales, que son impulsadas por las políticas públicas asociadas con la Revolución Verde, las cuales 
resultan observables en gran parte de Latinoamérica (Alemany y Sevilla, 2007). Sin embargo, la medición de los impactos que corresponden a la implementación de estas prácticas en los predios de agricultura familiar ha sido escasamente abordada debido a la complejidad que representa metodológica y disciplinarmente, y a que aún es difícil cuantificar efectos que tengan consecuencias razonables a mediano o largo plazo, tal como se deben analizar estas prácticas, es decir: como un cambio de paradigma que transita desde el convencionalismo de la productividad hasta la lógica de la sustentabilidad.

En Chile el desarrollo y las proyecciones futuras de la agricultura familiar se encuentran ligados a los planes y programas implementados por el Instituto de Desarrollo Agropecuario (Indap), entidad estatal que funciona bajo el alero del Ministerio de Agricultura y que desde sus inicios desarrolló acciones que buscaban, por una parte, promover la modernización y, por otra, la industrialización de la agricultura y la reducción de las tasas de pobreza del campesinado mediante estrategias convencionales de extensionismo que corresponden al modelo Norteamericano: alternativas que se materializan en subsidios e incentivos económicos que apuntan al 'desarrollo’ de la región. Sin embargo, en sus lineamientos estratégicos 20I4-20I8, este modelo tradicional evidencia un cambio que reconoce la existencia de la agricultura que se emprende con un enfoque agroecológico, y que afirma que esta puede ser considerada un ejemplo de buenas prácticas agrícolas, las cuales dan aportes significativos a la sustentabilidad ambiental (Indap, 2014). Considerando que el $65 \%$ de la agricultura familiar chilena recibe asesoría técnica directa del Indap y que el enfoque agroecológico que se busca propiciar ha sido identificado en comunas de montaña como la que se aborda en este estudio, es relevante analizar las características de producción de estos sistemas agrícolas. En consecuencia, el objetivo de esta investigación es indagar sobre la medida en que estas prácticas aportan a la sustentabilidad de los predios que han adoptado este enfoque agroecológico, en comparación con aquellos que desarrollan prácticas agrícolas con un enfoque convencional en Curarrehue, una comuna rural de montaña de la Región de la Araucanía en el sur de Chile. Lo anterior corresponde a la comprensión de la sustentabilidad que es entendida como un hecho holístico: una nueva forma de diálogo y de entendimiento entre hombre y naturaleza, que se basa en la búsqueda del bienestar y el progreso conjunto, asociado a las dimensiones económica, ambiental y social (Leff, 2000). Por su parte, la dimensión operativa de este enfoque se realizará mediante una evaluación sistémica de indicadores que considera los atributos básicos de sustentabilidad propuestos 
por Masera, Asteir y Lopéz-Ridaura (1999), a saber: productividad, estabilidad, confiabilidad, resiliencia, adaptabilidad, equidad, autogestión.

\section{Agricultura familiar de montaña y las complejidades de la sustentabilidad}

La Revolución Verde, definida por la Organización de las Naciones Unidas para la Alimentación y la Agricultura (FAO, 1996) como el conjunto de tecnologías orientadas a mejorar el rendimiento y las técnicas de gestión agrícola desarrolladas entre 1960 y 1980 en países en vías de desarrollo, es un proceso que sustenta su lógica en el rendimiento económico de los cultivos agrícolas. Tal como lo plantean Rosset, Collins y Moore (2000), dicho estudio no midió las consecuencias ambientales y sociales que conllevaría el abusivo uso de fertilizantes y plaguicidas químicos en la producción agrícola, así como tampoco consideró la importancia de mantener la biodiversidad local de cada territorio, lo cual provocó además una fuerte polarización cuyos principales aspectos resultaron notables en la gran industria agrícola y los pequeños productores, todo lo cual afectó la rentabilidad y la sustentabilidad de la agricultura familiar.

Para los países latinoamericanos, la Revolución Verde ha acarreado también cambios importantes en la estructura de la propiedad de la tierra; transformaciones que favorecen el desarrollo de monocultivos comerciales en amplias extensiones de terreno y las cuales benefician la concentración de tierras de tal modo que, por tanto, involucran disputas por el acceso a ellas. Por otro lado, Borsdorf (1995) observa otros tipos de consecuencias en este proceso: efectos tales como el aumento de la dependencia económica latinoamericana, que son relevantes en tanto que los países de la región no poseen recursos energéticos suficientes y deben importarlos a los del norte a elevados costos. Es así como la Revolución Verde ha consolidado relaciones de intercambio fundamentales en el comercio mundial: ajustes que involucran el abaratamiento de materias primas (agrarias) y la elevación de costos de las mercancías industriales que terminan siendo necesarias para la actividad, generando una economía de 'bigh energy input' que es formulada de acuerdo con el modelo norteamericano: un proceso que tiene como consecuencia el aumento de la brecha de desigualdad que existe entre los países ricos y los pobres. De igual manera este modelo se ha materializado en las políticas públicas que tienden a la homogenización de los planes de intervención en el territorio, sin considerar las especificidades locales. 
Dado que los impactos de la Revolución Verde son observables en múltiples aristas de la actividad agrícola, al igual que en las dinámicas del mundo rural, es necesario contextualizar tanto el análisis de las prácticas agrícolas convencionales que son promovidas por esta, como las agroecológicas en la discusión que versa sobre la sustentabilidad, que es entendida como un objetivo a alcanzar a mediano y largo plazo. El informe de la comisión World Commision on Environment and Development (1987) la define como la capacidad que ha desarrollado el sistema humano para satisfacer las necesidades de las generaciones actuales, sin comprometer los recursos ni oportunidades para el crecimiento y el desarrollo de las generaciones futuras. A ello Calvente (2007) añade que la sustentabilidad corresponde a la habilidad de lograr una prosperidad económica sostenida a lo largo del tiempo; una coyuntura en medio de la que se protegen al mismo tiempo los sistemas naturales del planeta y se provee una alta calidad de vida para las personas. En este contexto, Tommasino y Hegedüs (2006) señalan que la dimensión social de dicho proceso debe ser entendida como el nexo que se establece entre múltiples dimensiones económicas y ambientales. Las diferentes prácticas agrícolas que se desarrollan en el mundo rural corresponderán, entonces, a la materialización de dicho nexo; prácticas que tendrán trayectorias de desarrollo e impactos distintos en el contexto de la sustentabilidad de la actividad agrícola.

$\mathrm{Al}$ respecto, Altieri y Nichols (2000) señalan que el movimiento agroecológico y sus prácticas conforman un nuevo enfoque de desarrollo agrícola, y un nuevo modelo de desarrollo rural en el cual son consideradas las complejidades de las agriculturas locales, y que se propone ampliar los objetivos agrícolas para alcanzar la sustentabilidad; una perspectiva que ademas rompe con el enfoque jerárquico que opone al técnico y al campesino, y que fomenta el diálogo de saberes entre productores, al igual que aborda la producción agrícola con un enfoque holístico del sistema agropecuario (Guzmán et al, 2000, en Sevilla y Soler, 2009).

Si bien la agricultura familiar de montaña presenta dificultades para la generación óptima de criterios de producción, debido a factores biofísicos como el incremento generalizado de las temperaturas y al aumento en la frecuencia de eventos extremos (sequías e inundaciones) en áreas montañosas (Beniston, 2003; IPCC, 2007); a la degradación de suelos por deforestación (Marchant y Sánchez 20II); a la habilitación de tierras para proyectos urbanos (Vargas, Castro y Ziadat, 2015), y al éxodo rural (Delgado, 2008), puede ser vista como un nicho que apunta al cambio de los paradigmas que rodean la actividad. En ese sentido, la implementación de prácticas agrícolas que rescatan las formas tradicionales de producción, valorizan los saberes tradicionales y proponen simultáneamente una diversificación de los ingresos 
prediales -mediante el desarrollo de otras actividades económicas como, por ejemplo el turismo rural-, transformando así las debilidades de estos lugares en oportunidades de desarrollo local (Wymann von Dach, Romeo, Vita, Wurzinger y Kohler, 2013).

Las dificultades para evaluar cómo estas prácticas contribuyen a la generación de sistemas agrícolas más sustentables, radica en la necesidad de evaluaciones multitemporales e interdisciplinarias (Gutiérrez, Aguilera y González, 2008). Asimismo, Petersen (2003) enfatiza en la necesidad de realizar estudios de caso de experiencias exitosas y en la generación de agroecosistemas económicamente viables, socialmente justos y ecológicamente saludables. Al respecto, Ortiz y Astier (2003) describen ocho casos exitosos que se basaron en la metodologia Mesmis para analizarlos: estos corresponden a las variantes de manejo de milpas de maíz en la zona maya de Yucatán, y a la ovinicultura mejorada, dentro de un sistema agro-silvo-pastoril, y manejada por pastoras tzotziles en los Altos de Chiapas, al igual que a la producción de maíz asociada con el frijol bajo un sistema de rotación con chícharo en la Región Purhépecha del estado de Michoacán para el caso de México; a los sistemas agro-silvícolas mejorados, que se basan en la conservación de suelos en la comunidad indígena de Chullpa K’asa, en Cochabamba, y a los sistemas agroforestales que se despliegan en la comunidad indígena de Tres Cruces en Cochabamba, para la sierra de Bolivia. Asimismo, se involucra la producción de algodón orgánico en Tarapoto, San Martín, y su correspondiente sistema de producción de limón en el valle alto de Piura en Perú; y la agricultura familiar que se desarrolla en el sector rural parabiano, en Brasil. Estos ejemplos dan cuenta del esfuerzo que se desenvuelve con el fin de aprovechar los recursos naturales con una mayor racionalidad ecológica, utilizando los saberes locales, no solo en aras de la generación de mayores ingresos económicos, sino con los fines de mantener el equilibrio entre los sistemas socionaturales y de promover su sustentabilidad.

\section{Metodología}

\section{I Área de estudio}

Curarrehue (figura I) es una comuna de montaña ubicada en la región de la Araucanía, entre los $38^{\circ} 55^{\prime}$ y los $39^{\circ} 38^{\prime}$ de Latitud Sur, y los $71^{\circ} 25^{\prime}$ y los $71^{\circ} 45^{\prime}$ de Longitud Oeste (Municipalidad de Curarrehue, 2009). Su altitud promedio varía entre los 390 m.s.n.m y los i.600 m.s.n.m, siendo el punto más alto su acceso al volcán Lanín, con 3.747 m.s.n.m. Posee un clima del tipo templado cálido, con estación 
seca corta (menos de 4 meses). Su precipitación media anual supera los $2000 \mathrm{~mm}$, y su temperatura fluctúa ente los $15 . \mathrm{I}^{\circ} \mathrm{C}$, en los meses cálidos, y los $6.0^{\circ} \mathrm{C}$ en los meses fríos. Se presentan temperaturas mínimas bajo los $3^{\circ} \mathrm{C}$ desde mayo hasta octubre, ocurriendo heladas frecuentemente. En ese contexto existe una variación de precipitaciones que oscila entre los 1.500 y los $2.500 \mathrm{~mm}$ al año; fluctuaciones que corresponden a una humedad relativa cuyo promedio es del $85 \%$ (Red Reserva Biosfera Araucarias, 2010). Se caracteriza por ser un territorio de montaña (Zona Lacustre) habitado por un $72 \%$ de población rural y un $50.6 \%$ de población indígena (Red Reserva Biósfera Araucarias, 2010). Existe una baja oferta laboral, y la producción agropecuaria corresponde al autoconsumo. Sin embargo, múltiples iniciativas de turismo son fomentadas por el municipio (e.g. Aldea Cultural Mapuche Trawupeyun) y por otras entidades autónomas (e.g. Red de Turismo Mapuche, Feria Walung y la comunidad Juan de Dios Ancamil); iniciativas que buscan generar nichos económicos locales, vinculando la agricultura sustentable con turismo rural y la cocina tradicional (Pacheco, Henríquez, Sampaio y Oyarzún, 20II).

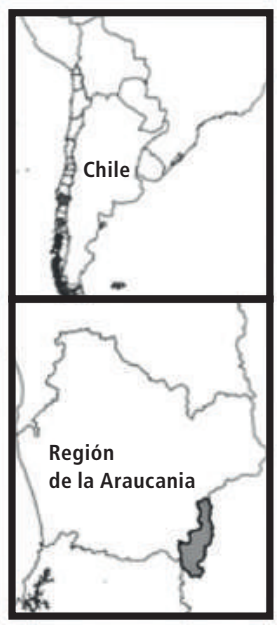

Leyenda
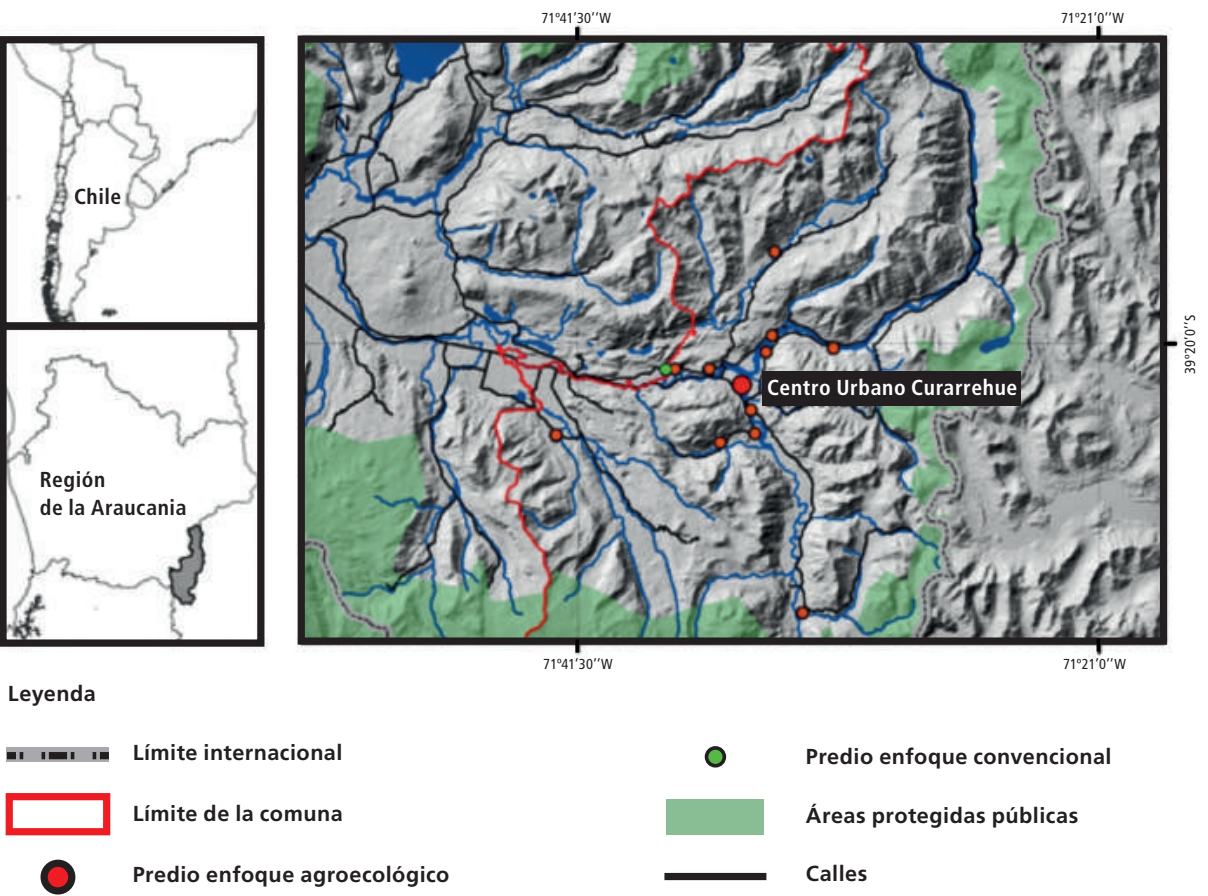

Figura l: mapa de la comuna de Curarrehue FuENTE: elaboración propia 


\subsection{Marco para la evaluación de sistemas de manejo de recursos naturales que incorpora indicadores de sustentabilidad (Mesmis)}

En el presente estudio se utilizó la metodología Mesmis, que fue propuesta por Masera, Astier y Lopéz-Ridaura (1999); procedimiento que tiene como objetivo comparar un sistema de manejo de referencia ortodoxo con uno alternativo. Así pues, para fines de este estudio se lo consideró como un procedimiento alternativo a los sistemas prediales, cuyo enfoque productivo agroecológico y de referencia a los predios corresponde a un enfoque productivo convencional.

\subsection{Selección de los agroecosistemas}

La selección de los casos de estudio se realizó con la ayuda de informantes clave locales, en este caso funcionarios del Programa de Desarrollo Territorial Indígena (PDTI) del Indap. Se identificaron II sistemas prediales de enfoque productivo agroecológico, nueve de ellos de origen indígena, y un predio de enfoque productivo convencional también de origen indígena. Los predios de enfoque productivo agroecológico seleccionados cumplían con el enfoque agroecológico propuesto por Altieri y Toledo (20II), el cual se caracterizaba por el uso de policultivos, de semillas y de razas de animales criollas, así como por la rotación de cultivos, el control natural de plagas y el uso de abonos orgánicos. En tanto, el enfoque convencional fue selecionado con base en información que había sido proporcionda por los informantes del PDTI, y se caracterizó por el uso de fertilizantes químicos, pesticidas y monocultivos.

\subsubsection{Caracterizacion de los agroecosistemas}

A lo largo de un periodo de 12 meses se realizaron entrevistas semiestructuradas que permitieron contemplar las cuatro estaciones del año, y su correspondencia con cada uno de los agricultores que son parte de los predios seleccionados (tabla I). Asimismo se aplicó una ficha de caracterización de cada unidad familiar, un procedimiento mediante el cual se evaluó el estado de las prácticas que fueron desarrolladas en las dimensiones ambiental, económica y social, para apuntar a los ejes del desarrollo sustentable. Con la información recolectada se definió como Unidad Productiva al predio principal de residencia de los productores, y para cada Unidad Productiva se elaboraró un diagrama de flujo, que contemplaba la identificación de los principales subsistemas productivos con los componentes de cada subsistema. Posteriormente, se interelacionaron los subsistemas mediante flujos que correspondían a las entradas y salidas de insumos -materiales e inmateriales-: este proceso permitió la caracterizacion de cada subsistema y con base en ello se procedió a identificar los 
puntos críticos, que son traducidos en las fortalezas y debilidades de cada predio, mediante criterios de diagnóstico que asocian a los siete atributos de sustentabilidad (tabla 2) entregados por Mesmis (productividad, estabilidad, confiabilidad, resiliencia, adaptabilidad, equidad, autogestión).

Tabla 1. Principales características y rubros de los predios seleccionados

\begin{tabular}{|c|c|c|c|c|c|c|c|}
\hline \multirow[t]{2}{*}{ Predio } & \multirow[t]{2}{*}{ TAMAÑO } & \multirow[t]{2}{*}{ Altitud } & \multicolumn{4}{|c|}{ Principales Sistemas PRODUCTIVOS } & \multirow{2}{*}{$\begin{array}{l}\mathrm{N}^{\circ} \mathrm{DE} \\
\text { INTEGRANTES }\end{array}$} \\
\hline & & & Pecuario & Agrícola & Forestal & Artesanías & \\
\hline $\mathrm{EC}$ & $4 \mathrm{ha}$ & $385 \mathrm{~m}$ & $\checkmark$ & $\checkmark$ & $\checkmark$ & - & 4 \\
\hline A & $4 \mathrm{ha}$ & 430 & $\checkmark$ & $\checkmark$ & - & $\checkmark$ & 4 \\
\hline B & $3,8 \mathrm{ha}$ & 470 & $\checkmark$ & $\checkmark$ & $\checkmark$ & $\checkmark$ & 2 \\
\hline $\mathrm{C}$ & 2 ha & 395 & $\checkmark$ & $\checkmark$ & - & & 5 \\
\hline $\mathrm{D}$ & I ha & 400 & $\checkmark$ & $\checkmark$ & $\checkmark$ & $\checkmark$ & 5 \\
\hline $\mathrm{E}$ & 4,5 ha & 435 & $\checkmark$ & $\checkmark$ & $\checkmark$ & $\checkmark$ & 3 \\
\hline $\mathrm{F}$ & I3 ha & 670 & $\checkmark$ & $\checkmark$ & $\checkmark$ & $\checkmark$ & 2 \\
\hline $\mathrm{G}$ & $4 \mathrm{ha}$ & 500 & $\checkmark$ & $\checkmark$ & $\checkmark$ & $\checkmark$ & 5 \\
\hline $\mathrm{H}$ & I ha & 390 & $\checkmark$ & $\checkmark$ & - & $\checkmark$ & 2 \\
\hline I & $0,5 \mathrm{ha}$ & 470 & - & $\checkmark$ & - & $\checkmark$ & 4 \\
\hline $\mathrm{J}$ & 4,5 ha & 490 & $\checkmark$ & $\checkmark$ & $\checkmark$ & - & 2 \\
\hline $\mathrm{K}$ & $4,5 \mathrm{ha}$ & 510 & $\checkmark$ & $\checkmark$ & $\checkmark$ & - & 5 \\
\hline
\end{tabular}

Fuente: elaboración propia

Tabla 2. Atributos de la sustentabilidad según Mesmis

\begin{tabular}{lll}
\hline Atributo & Criterio de diagnostico & Área de evaluación \\
\hline Productividad & Eficiencia & Económica \\
\hline Estabilidad & Condicion productiva del suelo & Ambiental \\
\cline { 2 - 3 } $\begin{array}{l}\text { Renfiabilidad } \\
\text { Resiliencia }\end{array}$ & Manejo de riesgo & Económica \\
\cline { 2 - 3 } & Capacidad de cambio e innovación & Social \\
\cline { 2 - 3 } & Vulnerabilidad & Social \\
\hline Adaptabilidad & Capacidad de cambio e innovación & Ambiental \\
\cline { 2 - 3 } & Diversidad de actividades economicas & Económica \\
\hline Equidad & Equidad & Social \\
\hline Autogestión & Autosuficiencia & Económica \\
\cline { 2 - 3 } & Planificación & Social
\end{tabular}

FuENTE: elaboración propia 


\subsubsection{Selección de indicadores}

Una vez detectadas las fortalezas y debilidades de cada uno de los temas estudiados, se construyeron tablas cuyos indicadores de sustentabilidad fueron elaborados teniendo como base los criterios de diagnóstico antes mencionados (tabla 2). Cada indicador responde a un punto crítico que fue detectado de acuerdo con la caracterización de los sistemas prediales y a su vez es parte de una de las tres áreas de evaluación del estudio (ambiental, social y económica), con lo que se generaron i6 indicadores (figura 2).

Dicha información se recabó mediante entrevistas semi-estructuradas cuya realización fue llevada a cabo en cada uno de los predios que fueron visitados.

\begin{tabular}{|c|c|c|}
\hline Indicadores ambientales & Indicadores económicas & Indicadores sociales \\
\hline $\begin{array}{l}\text { Manejo de suelo } \\
\text { con cobertura vegental }\end{array}$ & $\begin{array}{l}\text { Pluriactividad } \\
\text { del agroecosistema }\end{array}$ & $\begin{array}{l}\text { Grado de participación } \\
\text { en organizaciones sociales }\end{array}$ \\
\hline Tipo de labranza & $\begin{array}{l}\text { Composición del ingreso } \\
\text { familiar }\end{array}$ & $\begin{array}{l}\text { Número de alternativas } \\
\text { de comercialización }\end{array}$ \\
\hline $\begin{array}{l}\text { Criterio de agregado } \\
\text { de nutrientes }\end{array}$ & $\begin{array}{l}\text { Nivel de satisfacción } \\
\text { de necesidades básicas }\end{array}$ & $\begin{array}{l}\text { Apoyo o respaldo técnico } \\
\text { del agrosistema }\end{array}$ \\
\hline $\begin{array}{l}\text { Utilización de abonos } \\
\text { orgánicos }\end{array}$ & $\begin{array}{l}\text { Autoabastecimiento } \\
\text { alimenticio }\end{array}$ & $\begin{array}{l}\text { Visión y pertinencia del } \\
\text { agrosistema }\end{array}$ \\
\hline $\begin{array}{l}\text { Eficiencia del sistema } \\
\text { de riego }\end{array}$ & & $\begin{array}{l}\text { Nivel de planificación } \\
\text { y registros en la gestión }\end{array}$ \\
\hline $\begin{array}{l}\text { Sistema de } \\
\text { almacenamiento de agua }\end{array}$ & & $\begin{array}{l}\text { Participación familiar } \\
\text { en la toma de decisiones }\end{array}$ \\
\hline
\end{tabular}

Figura 2. Indicadores de sustentabilidad que se basaron en la metodología Mesmis FUENTE: elaboración propia

\subsubsection{Estandarización general de indicadores}

Para analizar los resultados se estandarizaron los indicadores mediante escalas de valorización de indicadores* en rangos de o a 5 , correspondiendo a 5 los grados máximos de sustentabilidad y a o la nula sustentabilidad (tabla 3 ).

TABla 3. Categorías de valoración estandarizadas

\begin{tabular}{lll}
\hline \multicolumn{2}{c}{ VAlor numérico del indicador } & Descripción \\
\hline 5 & Ideal \\
\hline 4 & Alto \\
\hline 3 & Medio \\
\hline 2 & Bajo \\
\hline I & Muy bajo \\
\hline 0 & Nulo \\
\hline
\end{tabular}

FuENTE: elaboración propia 
2.2.5 Adaptación y estandarización de indicadores alusivos al caso de estudio Mediante un proceso de calibración de la metodología que fue propuesta por Mesmis, los 16 indicadores que fueron escogidos con base en las fortalezas y debilidades de cada agroecosistema fueron adaptados y estandarizados para dar cuenta de las especificidades locales del área de estudio, y de las unidades prediales con las que se trabajó. Para ello la estandarización se realizó de acuerdo con dos métodos que correspondieron a i) la consulta de bibliografía especializada y ii) la implementación de un panel de expertos compuesto por técnicos de los programas de fomento, así como por los mismos productores de los predios. Lo anterior permitió definir el desempeño ideal de cada indicador. En el anexo I se muestran los rangos de estandarización de cada indicador de sustentabilidad.

\subsection{Descripción de indicadores ambientales}

\section{Manejo del suelo con cobertura vegetal}

La cobertura vegetal evita la erosión del suelo y contribuye a mantener su humedad, por ello se consideró que tenía un desempeño ideal dado que su indicador correspondió al ıo० \% de cobertura vegetal del suelo (Pérez, Valdés y Ordaz, 2012).

\section{Tipo de labranzas}

La labranza tradicional considera que hay un constante desgaste del suelo por el volteo de la tierra, y tal proceso corrompe los equilibrios propios de los microorganismos presentes en él (Inostroza, 2009). Por tanto, el estudio consideró que había un desempeño ideal del indicador ante la escasa labranza del predio.

\section{Criterio de agregado de nutrientes}

El estudio consideró que un desempeño ideal del indicador podía corresponder al agregado de nutrientes que estaba respaldado por un previo análisis del suelo, así como por las recomendaciones técnicas que eran provistas por un experto (FAO, 2002).

\section{Utilización de abonos orgánicos}

El desempeño ideal del indicador correspondió a la mayor variedad de abonos orgánicos disponibles, como guano, compost, humus, bokachi, guano compostado o restos vegetales (Altieri M. y Nicholls C., 2000). 


\section{Eficiencia del sistema de riego}

El agua es un recurso escaso y fundamental, por tanto, su uso eficiente, que corresponde a la tecnificación del riego por goteo, fue considerado como un desempeño ideal del indicador (FAO, 2013).

\section{Sistema de almacenamiento de agua}

El almacenamiento de agua se ha transformado en una acción estratégica idónea para enfrentar el cambio climático: por ello se consultó a los agricultores por cuál era la capacidad de almacenamiento de agua del predio, considerándose como un desempeño ideal del indicador el que permitía que el predio pudiera cubrir las necesidades de animales y vegetales (FAO, 2013).

\subsection{Descripción de indicadores económicos}

\section{Pluriactividad productiva del agroecosistema}

Se consideró como pluriactividad a cualquier actividad no agrícola que generara ingresos extras a la unidad familiar (Schneider, 2009). Las principales actividades detectadas en la comuna de Curarrehue corresponden a la realización de artesanías, la elaboración de conservas, la orfebrería, la cocinería tradicional, el turismo, la mueblería, la apicultura, la elaboración de accesorios de vestimenta, la ganadería y los manejos forestales, siendo un desempeño ideal del indicador el que permita optar a cinco o más actividades dentro del agroecosistema.

\section{Composición del ingreso familiar}

Un análisis hecho por Qualitas (2009) con base en el VII Censo Agropecuario y Forestal chileno indica que solo un $30 \%$ de la pequeña agricultura obtiene más del $50 \%$ de ingresos por actividades del predio, y en el $52 \%$ de los casos restantes representa menos del $25 \%$ de los ingresos. Por tanto, y considerando que un escenario ideal de composición del ingreso familiar estaría dado cuando el roo \% de los ingresos agrícolas proviniera de las actividades intraprediales -y en vista de los datos anteriores- se observó como un desempeño ideal del indicador el que al menos el 60 $\%$ de los ingresos proviniera de actividades ligadas al predio.

\section{Nivel de satisfacción de las necesidades básicas}

En Chile la medición de las necesidades básicas se efectúa mediante la encuesta de Caracterización Socioeconómica Nacional (Casen), la cual no solo considera los ingresos 
sino además cuatro dimensiones adicionales para medir la pobreza, a saber: la educación, la salud, el trabajo y la seguridad social ligada a la vivienda (Ministerio de Desarrollo Social, 2015). Cada ítem esta definido con base en la carencia de algún bien o servicio, por lo que la ausencia de carencias fue considerada como un desempeño ideal del indicador.

\section{Autoabastecimiento alimenticio}

Se utilizó como indicador de autoabastecimiento el cumplimento mínimo de la producción de una alimentación balanceada que fue propuesta por la $\mathrm{FAO}$ (2002) con base en alimentos básicos, ricos en energía y en proteína, y que contenían vitaminas y minerales. En ese contexto, el desempeño ideal del indicador correspondió al que oscilaba entre el 80 y el $100 \%$ del autoabastecimiento alimenticio.

\subsection{Descripción de indicadores sociales}

\section{Grado de participación en organizaciones sociales}

Contreras (2000) plantea que mediante la organización y acción colectiva de la comunidad y de los agentes de desarrollo, se pueden crear instancias de desarrollo local que involucran la generación de redes y de capacidades de gestión sociales y productivas.

En la comuna de Curarrehue fue posible identificar al menos cinco formas de agrupación: junta de vecinos, comunidades indígenas, agrupación productiva por rubro, comité de agua potable rural (APR) y cooperativas. En consecuencia, se consideró que el desempeño ideal del indicador correspondía a la participación en tres organizaciones, categorizando además la participación en las organizaciones en distintos grupos (dirigente, socio activo, socio pasivo).

\section{Número y alternativas de comercialización}

En la medición se consideraron cuatro formas principales de comercialización: venta directa en el predio, venta a intermediario, venta a mercado mayorista y venta en feria. Considerando que la venta en feria y mercado mayorista es la que corresponde a un mayor margen de ganancia para los productores (Odepa, 20I2), se consideró como desempeño ideal del indicador la venta directa en las ferias.

\section{Apoyo o respaldo técnico a la unidad predial}

En sus políticas de fomento productivo el Indap ha incrementado en los últimos años la cobertura de público objetivo de sus programas a cifras del 80 \% (Indap, 20I4). En 
consecuencia, bajo el enfoque de este este estudio existían altas probabilidades de que los entrevistados recibieran asesoría técnica de parte del Estado. En tanto, según Berdegué (20I4) el acceso a otros tipos de apoyo y/o tecnologías solo corresponde a un $3 \%$ en el contexto de la agricultura familiar.

Nazif (2009) considera que para un correcto desarrollo de la agricultura familiar es necesario el apoyo técnico mediante insituciones públicas que permiten la generación de una red cuya articulación con los mercados podría servir como base del desarrollo local; un proceso que podría apuntar a nuevas disminuciones de las 'fallas del mercado’. Bajo esta premisa se consideró que, tanto usuarios de instrumentos de fomento productivo como participantes de proyectos productivos de financiamiento estatal o privado, podrían ser vistos como componentes esenciales para el sistema pecuario, de modo que podría observarse que un desempeño ideal del indicador corresponde a la asistencia permanente y a la participación activa en proyectos silvoagropecuarios.

\section{Visión y pertinencia del agroecosistema}

Se consideró como desempeño ideal del indicador que los productores tuvieran una visión de pertenencia a su territorio, y que buscaran un desarrollo económico y social que no solo beneficiara a su familia, sino también a la comunidad y al ecosistema. Lo anterior se relaciona con el planteamiento de Ellis y Biggs (200I), que alude a la importancia de que los actores se empoderen del territorio y que generen desarrollo de abajo hacia arriba (enfoque bottom-up).

\section{Nivel de planificación y registros en la gestión del agroecosistema}

La planificación predial a largo plazo (Io-20 años) permite visualizar los objetivos a cumplir, y cómo estos objetivos se van transformando en metas cumplidas (Olivares, Smith-Ramírez, Zenteno y Fernández, 2009). Se consideró como ideal que los productores tuvieran identificados los recursos disponibles, la capacidad productiva, una programación de actividades anuales y un registro de ingresos y egresos por concepto de la producción.

\section{Participación familiar en la toma de decisiones}

En el campesinado occidental existe un modelo de patriarcado en el que el hombre es el principal tomador de decisiones. Sin embargo, Pérez y Montiel (2013) señalan que el enfoque agroecológico no problematiza las diferencias de género y utiliza términos neutrales para referirse al agroecosistema o campesinado, proponiendo 
una recostruccion del tejido social rural en la que los roles correspondientes a las acitivdades pecuarias no son femeninas ni masculinas, sino actividades compartidas que proporcionan equidad en la familia rural. Se consideró entonces como desempeño ideal del indicador que dentro del predio las decisiones fueran consultadas a todos los integrantes de la familia, independientemente de quien fuera considerado para fines políticos o estadísticos el jefe de hogar.

Una vez fueron estandarizados y calculados los indicadores, se elaboraron gráficos radiales que permitían comparar los resultados de los predios de enfoque productivo agroecológico con los del predio, cuyo enfoque es convencional, y proceder así a la evaluación de la sustentabilidad predial.

\section{Resultados}

\section{I Caracterización de los sistemas alternativos y de referencia}

Como parte de la caracterización de los sistemas prediales para la dimensión ambiental, se consideraron aspectos como los usos del suelo y del agua; para la económica, los diferentes sistemas productivos que había dentro del predio, y para la social se consideró la participación en organizaciones, al igual que la asistencia técnica recibida. A diferencia de la agricultura agroecológica, la agricultura convencional involucra altos usos de fertilizantes y pesticidas químicos que se asocian a maquinaria pesada y que, en conjunto, degradan el suelo e impiden la retención de agua, así como además limitan la vida de los microorganismos. En el aspecto económico, el enfoque agroecológico presenta un subsistema extra denominado "artesanías", el cual valora la capacidad de la unidad predial de generar ingresos por vías alternativas. Por otro lado, en la dimensión social, el enfoque agroecológico valora, a diferencia de la perspectiva convencional, la participación en organizaciones sociales, dado que corresponde a un mayor capital social. Estos aspectos muestran que el enfoque agroecológico corresponde a una mayor amplitud de parámetros, y que además consideran múltiples aspectos del funcionamiento de la unidad productiva, que es vista como un sistema vivo y dinámico que se integra al territorio. La tabla 4 muestra los principales contrastes que existen entre los agroecosistemas de enfoque productivo agroecológico y de enfoque productivo convencional que fueron detectados con base en los diagramas de flujos prediales que habían sido realizados entre los subsistemas de cada caso de estudio. 
TABla 4. Comparación entre el sistema de referencia (enfoque productivo convencional) y los sistemas alternativos (enfoque productivo agroecológico) en relación a sus áreas de evaluación

\begin{tabular}{ll}
\hline $\begin{array}{l}\text { Agroecosistemas alternativos } \\
\text { (enfoque productivo agroecológico) }\end{array}$ & $\begin{array}{l}\text { Agroecosistemas de referencia (enfoque } \\
\text { productivo convencional) }\end{array}$ \\
\hline \multicolumn{2}{c}{ Dimensión Ambiental } \\
\hline
\end{tabular}

Cobertura vegetal: Cobertura vegetal $>90 \%$, en todas las estaciones del año, principalmente bosque nativo y praderas de pastoreo Tipo de labranzas: Principales manejos con medios manuales o de tracción animal, ocasionalmente usan tractor facilitado por el municipio Fertilización del suelo: Abundante uso de guano fresco, utilización de humus en invernaderos y huertas al aire libre. Algunos predios utilizan compost o guano compostado de oveja y gallina. Riego: Existe baja tecnificación del riego, asociado mayormente a la disponibilidad de uso de agua. Los predios con menor disponibilidad de agua hacen un uso más eficiente que aquellos que tienen mayor disponibilidad.

\section{Dimensión Económica}

Los predios presentan diferentes rubros productivos, detectándose los siguientes: Subsistema pecuario: Crianza de aves como gallinas y patos, tenencia de ovejas en la mayoría de los predios y ganado vacuno en solo algunos con mayor disponibilidad de terreno. También existe la cría por temporadas de cerdos para engordar. Subsistema agrícola: Principalmente de autoconsumo. La mayoría cuenta con un invernadero y huertas al aire libre. Los que tienen mayor disponibilidad de terreno realizan cultivos anuales de papa, maíz o legumbres. Subsistema forestal: Principalmente de bosque nativos, con manejos menores para autoconsumo. Subsistema "artesanías": Gran parte de los casos de estudio realizan artesanías y comida tradicional para vender y generar ingresos económicos, mezclando cultura tradicional indígena y popular.
Cobertura vegetal: Cobertura vegetal $>90 \%$, a excepción de los periodos de siembra, en los que el suelo queda descubierto. Tipo de labranzas: Uso de tractor para los cultivos anuales y manejo manual para invernadero. Fertilización del suelo: Uso de fertilizantes químicos tanto en cultivos anuales como en invernadero, asociado al guano de oveja fresco. Riego: Existe tecnificación de riego en invernadero y algunos cultivos al aire libre.
El predio de referencia igual presenta diferentes rubros, detectándose los siguientes: Subsistema pecuario: Presenta crianza de aves, principalmente gallinas y crianza de ovejas para autoconsumo y venta. Subsistema agrícola: Para auto consumo y para venta, tiene huerta al aire libre, invernadero y cultivos anuales de pradera, maíz, papas y legumbres. Subsistema forestal: Principalmente de bosque nativo, con manejo para venta por trozo en el predio. 


\begin{tabular}{ll}
\hline $\begin{array}{l}\text { Agroecosistemas alternativos } \\
\text { (enfoque productivo agroecológico) }\end{array}$ & $\begin{array}{l}\text { Agroecosistemas de referencia (enfoque } \\
\text { productivo convencional) }\end{array}$ \\
\hline
\end{tabular}

Dimensión Social

\begin{tabular}{ll}
\hline $\begin{array}{l}\text { Organizaciones sociales: Existen abundantes } \\
\text { organizaciones sociales, tales como: }\end{array}$ & $\begin{array}{l}\text { Organizaciones sociales: Baja participación, } \\
\text { agrupaciones de artesanos, agrupaciones }\end{array}$ \\
$\begin{array}{l}\text { laborales, comunidades indígenas, } \\
\text { juntas de vecinos y cooperativas. }\end{array}$ & $\begin{array}{l}\text { por parte décnica: } \text { Alta asistencia técnica } \\
\text { Asistencia técnica: } \text { Existe una alta asesoría }\end{array}$ \\
$\begin{array}{l}\text { técnica por parte del municipio e Indap a } \\
\text { la gran mayoría de los casos de estudio. }\end{array}$ & \\
\hline
\end{tabular}

FuENTE: elaboración propia

\section{2 Integración de resultados de los indicadores}

Para lograr comparar la sustentabilidad de los predios de enfoque productivo agroecológico con los enfoques productivos convencionales, se integraron los resultados en gráficos radiales, con base en la estandarización que correspondía a los predios enfoque productivo agroecológico, que por su parte puede ser verificada en la tabla 5 (ideal, alto, medio, bajo, muy bajo y nulo).

TABLA 5. Estandarización resultados predios enfoque productivo agroecológico

\begin{tabular}{lcccccc}
\hline Indicador & Ideal & Alto & Medio & Bajo & MuY bajo & Nulo \\
\hline $\begin{array}{l}\text { Manejo del suelo con } \\
\text { cobertura vegetal }\end{array}$ & 9 & 2 & - & - & - & - \\
\hline Tipo de labranzas & 5 & - & 6 & - & - & - \\
\hline Criterio de agregado de nutrientes & I & - & I0 & - & - & - \\
\hline Utilización de abonos orgánicos & 8 & - & 3 & - & - & - \\
\hline Sistemas de almacenamiento de agua & 5 & - & 5 & - & - & I \\
\hline Eficiencia de sistema de riego & 4 & - & 6 & - & - & I \\
\hline Pluriactividad del agroecosistema & 7 & I & 3 & - & - & - \\
\hline
\end{tabular}




\begin{tabular}{|c|c|c|c|c|c|c|}
\hline INDICADOR & IDEAL & Alto & Medio & BaJo & Muy bajo & Nulo \\
\hline Composición del ingreso familiar & 5 & 3 & I & 2 & - & - \\
\hline $\begin{array}{l}\text { Nivel de satisfacción de } \\
\text { necesidades básicas }\end{array}$ & 5 & 6 & - & - & - & - \\
\hline Autoabastecimiento alimenticio & 7 & 4 & - & - & - & - \\
\hline $\begin{array}{l}\text { Grado de participación en las } \\
\text { organizaciones sociales }\end{array}$ & 6 & 2 & - & 2 & I & - \\
\hline $\begin{array}{l}\text { Número y alternativas } \\
\text { de comercialización }\end{array}$ & 8 & 2 & - & - & - & I \\
\hline $\begin{array}{l}\text { Apoyo o respaldo técnico } \\
\text { del agroecosistema }\end{array}$ & 9 & 2 & - & - & - & - \\
\hline $\begin{array}{l}\text { Visión y pertinencia del } \\
\text { agroecosistema }\end{array}$ & 9 & - & - & - & 2 & - \\
\hline $\begin{array}{l}\text { Planificación y registros en la } \\
\text { gestión del agroecosistema }\end{array}$ & 5 & 4 & 2 & - & - & - \\
\hline $\begin{array}{l}\text { Participación familiar en } \\
\text { la toma de decisiones }\end{array}$ & 8 & - & 3 & - & - & - \\
\hline
\end{tabular}

\subsection{Grado de sustentabilidad de los agroecosistemas}

Mediante el criterio de valorización de los indicadores, el predio convencional (enfoque productivo convencional) obtuvo 49 de 80 puntos en el índice total de sustentabilidad (figura 3), lo cual fue calificado como un nivel medio de sustentabilidad. Los puntos críticos identificados correspondieron a la utilización de abonos orgánicos, la pluriactividad del agroecosistema, el grado de participación en organizaciones sociales y la visión y pertinencia del agroecosistema.

Por otro lado, los casos correspondientes a predios de enfoque productivo agroecológico que fueron analizados, obtuvieron una mayor puntuación en el índice de sustentabilidad total que la que correspondió al predio que operaba mediante un enfoque productivo convencional. De los once casos estudiados, el que obtuvo al resultado más alto alcanzó 76 de 80 puntos (A y B), y el más bajo 47 de 80 (K). Asimismo, nueve predios se categorizaron en un grado ideal de sustentabilidad, alcanzando un puntaje mayor a 64 (A, B, C, D, E, F, G, H, I), y dos obtuvieron un grado de sustentabilidad media, es decir obtuvieron valores que oscilaban entre 32 y 48 ( $\mathrm{J} \mathrm{y} \mathrm{K)}$. Con respecto a los puntos críticos que afectan la sustentabilidad de los 
predios que alcanzaron puntajes ideales, se destacan como tales el tipo de labranza, la eficiencia del sistema de riego y el criterio agregado de nutrientes. Por su parte, en aquellos predios de sustentabilidad media se detectaron falencias en el sistema de almacenaje de agua, así como falta de eficiencia del sistema de riego, menor grado de participación en organizaciones sociales, al igual que menores alternativas de comercialización y visión, y de pertinencia en el agroecosistema.
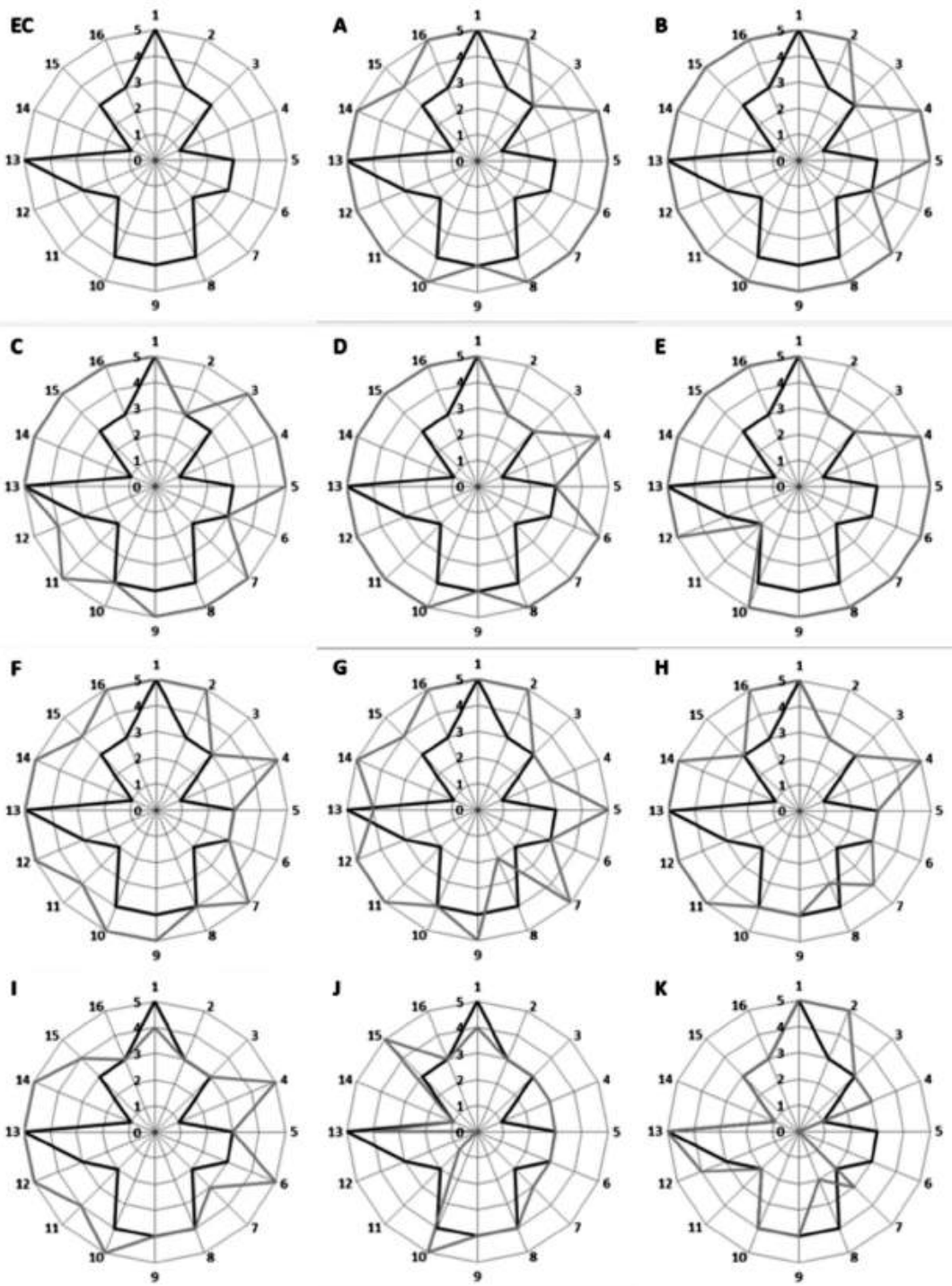

Figura 3. Representación gráfica de predios de enfoque agroecológico y de enfoque productivo convencional FuENTE: elaboración propia 


\section{Discusión}

$\mathrm{Al}$ caracterizar los predios de enfoque productivo convencional y enfoque productivo agroecológico es importante describir tanto las características tecnológicas y de manejo, como la situación socioeconómica (Ortiz y Astier, 2003). Al comparar estos dos tipos de sistemas prediales, observamos que las mayores diferencias se encuentran en tres ámbitos: i) los rubros productivos, ii) el uso de fertilizantes y iii) la participación en organizaciones sociales. Los predios de enfoque productivo agroecológico se caracterizan por ser pluriactivos, es decir, por presentar en su mayoría el desarrollo de actividades económicas complementarias como partes integrales de la actividad agrícola -elaboración de artesanías y comida tradicionales- de modo tal que este rubro cobra gran importancia para la generación de recursos extras. Benítez (2005) describe estas prácticas como una estrategia que en la práctica resulta exitosa para el desarrollo en las comunidades rurales. Lo anterior concuerda con los planteamientos de la FAO (2014), que por su parte señala que la diversificación de rubros productivos se constituye como un factor clave para la resiliencia de los sistemas agrícolas de montaña.

Si bien la diversificación de rubros es considerada por los teóricos como una clave para la consecusión de la sustentabilidad económica, las políticas públicas no siempre recogen este enfoque, dado que los subsidios e instrumentos de financiamiento se enfocan solamente en algunos rubros específicos. Un ejemplo de ello puede ser observado en Chile, en donde a pesar de que el Indap reconoce que el $60 \%$ de la agricultura familiar hace parte del rubro 'multiactivos', en sus planes de desarrollo otorga financiamiento a proyectos mono-rubristas que apuntan hacia la especialización de la agricultura familiar en algún rubro específico (Indap, 20I4).

Por otro lado, dentro de la búsqueda de la pluriactividad de la agricultura familiar, el giro turístico que corresponde con actividades complementarias como artesanías y comida tradicional campesina, puede ser visto como una respuesta a las demandas del mercado (Szmulewicz et al, 2012). Lo anterior puede ser considerado como el resultado de una influencia de la asistencia técnica estatal. En Chile, mediante planes que han sido impulsados por el Indap, se ha fomentado el rubro del turismo rural que corresponde al desarrollo de ferias como Expo Mundo Rural y de certificaciones locales como el Sello Manos Campesinas (Indap, 20I6). Estas actividades contribuyen a revitalizar las economías campesinas que acercan sus productos a nuevos consumidores. Sin embargo, lo anterior no está libre de polémicas, sino que constituye también prácticas que tienden a folclorizar rituales y tradiciones ancestrales que eventualmente someten sus premisas a la lógica del mercado. 
Por otro lado, en los predios que obtuvieron niveles medios de sustentabilidad, tanto en los convencionales como en los que corresponden a un enfoque agroecológico se vislumbra un punto clave a considerar: la falta de utilización de abonos orgánicos, indicador que disminuye, ante todo, la sustentabilidad del predio convencional. Por su parte, en los predios de enfoque productivo agroecológico, la deficiencia en las tecnologías de riego y labranza, que corresponden a la falta de criterio estandarizado de agregado de nutrientes, son los factores que más influyen en el resultado. Al respecto, Abbona y Sarandón (2014) enfatizan en la necesidad de la implementación de fertilizantes orgánicos que sirvan como mecanismo de manutención del suelo. Sin embargo, la práctica del uso de fertilización orgánica por sí sola no es suficiente, dado que es necesario llevar adelante un registro del estado del suelo para lograr un óptimo balance de nutrientes, algo que no siempre ocurre.

Por otra parte, la eficiencia de los sistemas de riego es relevante al momento de enfrentar la actual crisis hídrica (FAO, 2013). En los casos de estudios evaluados, los mismos productores son quienes explican que el déficit hídrico que tuvo lugar en Curarrehue es reciente; por tanto, no había existido la necesidad de tecnificar. Esta situación conforma un nuevo desafío que difiere de las situaciones que son evidentes en otras áreas montañosas como, por ejemplo, la provincia de Huarochirí en Perú, en donde desde tiempos prehispánicos se ha tecnificado el abastecimiento de agua para épocas de sequía mediante canales de infiltración de agua subterránea llamados “amunas" (Apaza, Arroyo y Alencastre, 2006). En este contexto, los productores de Curarrehue se encuentran en una fase de adaptación inicial que corresponde al acceso a recursos estatales que impulsan mecanismos de captación de recursos hídricos (cosecha de agua); un contexto en el que el fomento de técnicas que corresponden a esas premisas permite mantener el balance hídrico del suelo.

En el caso de los indicadores sociales, la mayoría de los predios -nueve de oncefueron diseñados con un enfoque agroecológico que correspondía a un alto grado de sustentabilidad. Este es un hecho relevante para la formación y el fortalecimiento del tejido y el capital social: un factor clave para el desarrollo del territorio, la colaboración y la formación de redes, todo lo cual es particularmente importante en territorios de montaña que se caracterizan por el aislamiento. Este tejido social puede llegar a incidir en el surgimiento de formas de producción sustentables o convencionales (La Vía Campesina, 20I3). Por su parte, solo dos unidades familiares de enfoque productivo agroecológico presentan niveles medios de sustentabilidad en este ámbito, lo cual puede deberse, según lo expuesto por Peredo y Barrera (2002), a las diversas etapas de transición agroecológica que componen dichos procesos. Estas 
unidades familiares serían notables en la fase inicial de este proceso, que es resultado del despertar del campesinado luego de la imposición de prácticas convencionales derivadas de la Revolución Verde, la cual no dio cabida a los pequeños agricultores, debido a la imposibilidad de acceder económicamente a la tecnologización del campo y a la compra de insumos (Ceccon, 2008).

Las unidades prediales que fueron analizadas en este estudio responden de forma similar a las evaluaciones de sustentabilidad que han sido realizadas en otros sistemas agrícolas de Latinoamérica; tal es el caso del Altiplano Central de México (Gutiérrez, Aguilera, González y Juan, 2012) o de los estudios que fueron realizados en Chile sobre los campesinos Pehuenches en Lonquimay (Báez, 2005), y sobre los campesinos del secano interior en Yumbel (Infante, 2013), en donde los conocimientos tradicionales campesinos son parte clave de la sustentabilidad social, existiendo variaciones locales respecto a la sustentabilidad económica y ambiental, debido a las variaciones geográficas características de cada estudio.

Estas variaciones geográficas demuestran lo importante que es la realización de los estudios de caso, los cuales mediante las metodologías que han sido adaptadas a la realidad de cada territorio, permiten recabar las particularidades de las prácticas que se asocian con la agricultura familiar, al igual que con los desafíos que esta enfrenta para ser más sustentable (Sepúlveda, Rodríguez, Echeverri y Portilla, 2003).

\section{Conclusión}

La agricultura familiar de Curarrehue es un ejemplo de agricultura de montaña que corresponde a múltiples prácticas tradicionales cuyo arraigo ancestral es propio de territorios aislados y de alta población indígena. Estas unidades prediales han sido intervenidas hasta hoy por los modelos extensionistas tradicionales del Estado chileno; intervenciones que se han materializado en planes y programas de desarrollo rural cuya aplicación ha sido dada a través del Indap, una institución que juega un rol crucial en los enfoques de desarrollo que se adoptan en la agricultura familiar chilena, toda vez que es la única institución que entrega subsidios y créditos a los habitantes rurales para el desarrollo de la actividad agrícola.

La mayoría de los involucrados en este estudio reciben asesoría directa del Indap, y las decisiones de manejo predial que toman están fuertemente vinculadas con las recomendaciones técnicas que han sido hechas por estos organismos; en consecuencia, el actual escenario de fortalecimiento de la política pública, que se orienta hacia la 
promoción de prácticas agroecológicas, se perfila como un contexto positivo para el fortalecimiento de dicho enfoque en este tipo de agricultura. Sin embargo, lo anterior puede ser considerado como una nueva forma de extensionismo cuyas trayectorias y efectos a futuro no es posible vislumbrar dado que, como con toda política pública, su continuidad está supeditada a los cambios de administración. Asimismo, es importante analizar y evaluar de qué modo estas dinámicas intervienen los territorios, y cómo la acción estatal puede operar como un promotor o un freno del desarrollo sustentable del medio rural.

Por otra parte, si bien la principal diferencia que existe entre ambos sistemas prediales es el uso o desuso de fertilizantes y plaguicidas químicos, existen otras prácticas que se vinculan con dichos procedimientos, como la comercialización de productos de manufactura casera por agricultores cuyas prácticas son emprendidas con un enfoque agroecológico, y que por ende resultan más sustentables. En ese contexto, la pluriactividad que caracteriza a esas prácticas permite la diversificación de ingresos, de modo que disminuye la dependencia que se centra en los escasos excedentes prediales agrícolas y en los subsidios estatales.

Las principales motivaciones que influyen en el desarrollo de esta actividad son el mejoramiento del entorno y la calidad de vida de la familia, que apuntan hacia la búsqueda de formas de asociación entre vecinos, que permiten mejorar las alternativas de comercialización. Lo anterior se puede reflejar fuertemente en la participación en ferias costumbristas de temporada que promueven los productos sanos y protegen el medio ambiente, valorizando de esta forma la geografía de montaña que los rodea y caracteriza.

Por su parte, la agroecología, que es considerada por Wezel et al. (2009) como una ciencia, práctica y movimiento social, corresponde a un nuevo paradigma del desarrollo rural que genera gran influencia en los territorios. Las prácticas agrícolas cuyo enfoque agroecológico es emprendido en territorios de montaña, aportan a su sustentabilidad; permiten generar redes de trabajo; llevan a fortalecer el empoderamiento de los campesinos, y son en suma mecanismos de adaptación eficaces ante el cambio climático (Torres, Frías y de la Torre, 20I4).

En consecuencia, la agricultura de montaña apunta principalmente a la subsistencia, pero es la base y el punto de partida de otros mercados que se asocian con ella como el turismo y la artesanía; por ello, este enfoque no solo apunta a la sustentabilidad ambiental, sino también a la económica y social, para que el agroecosistema sea en su conjunto resiliente y se adapte de mejor manera a los cambios ambientales globales. 


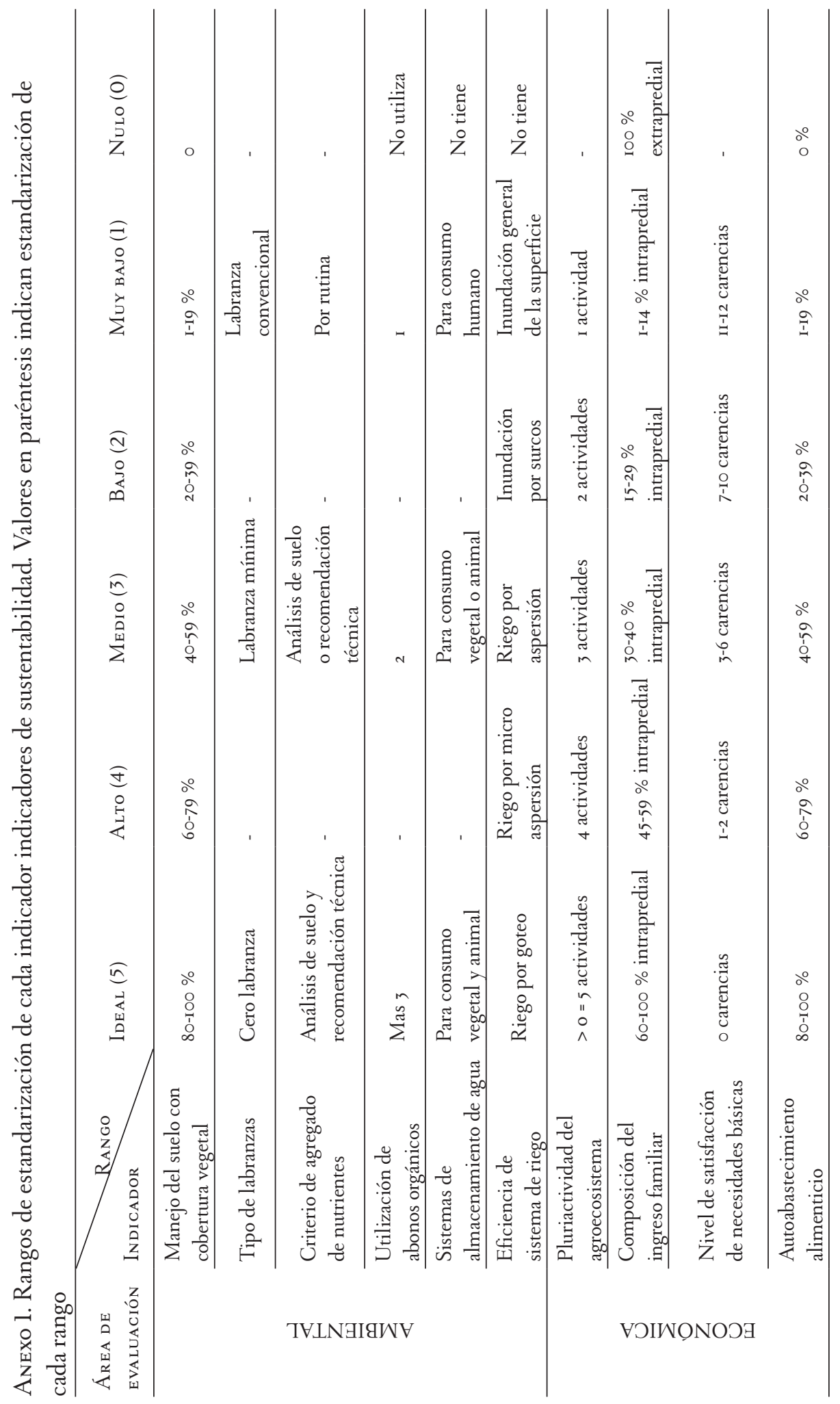




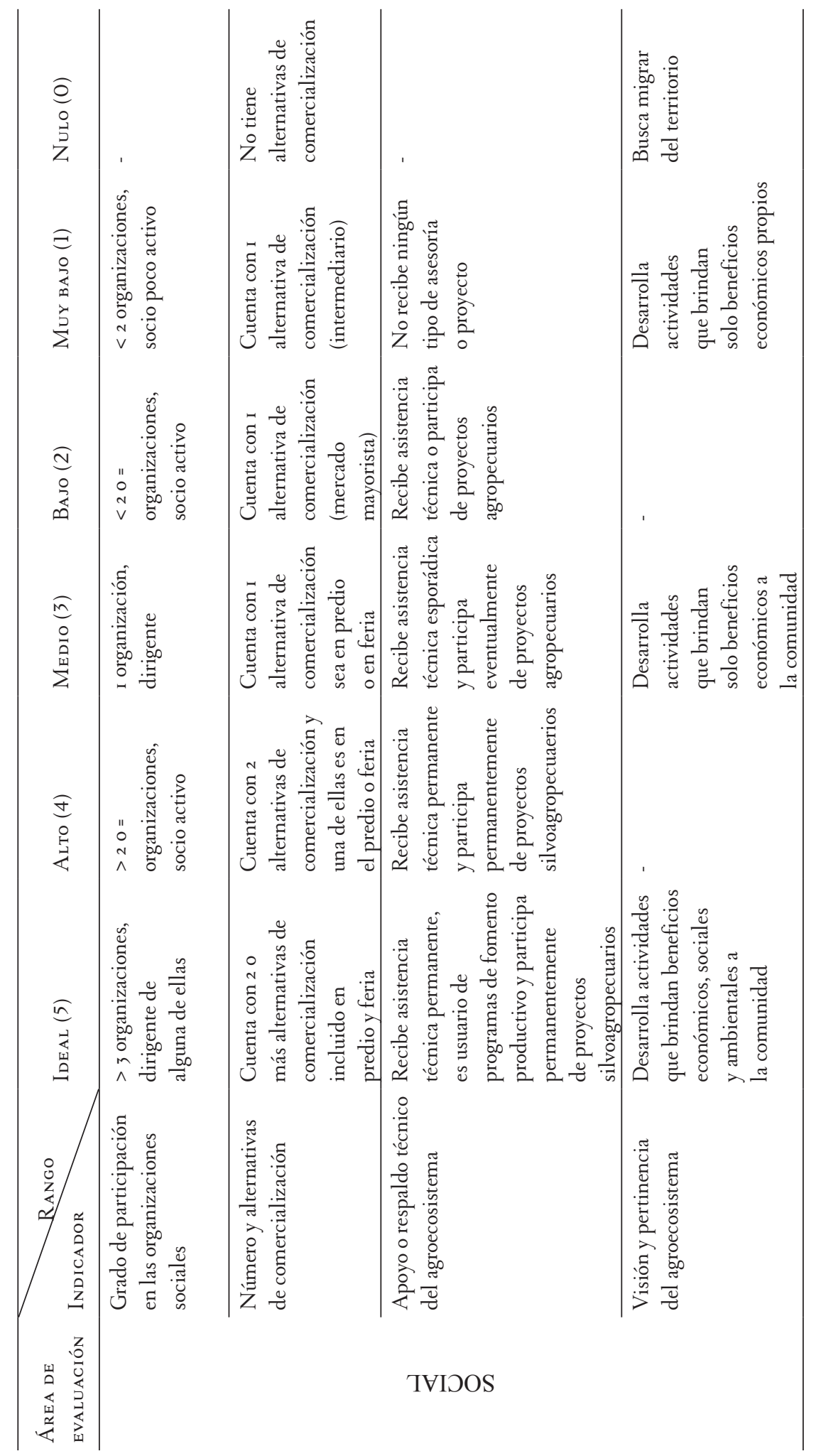




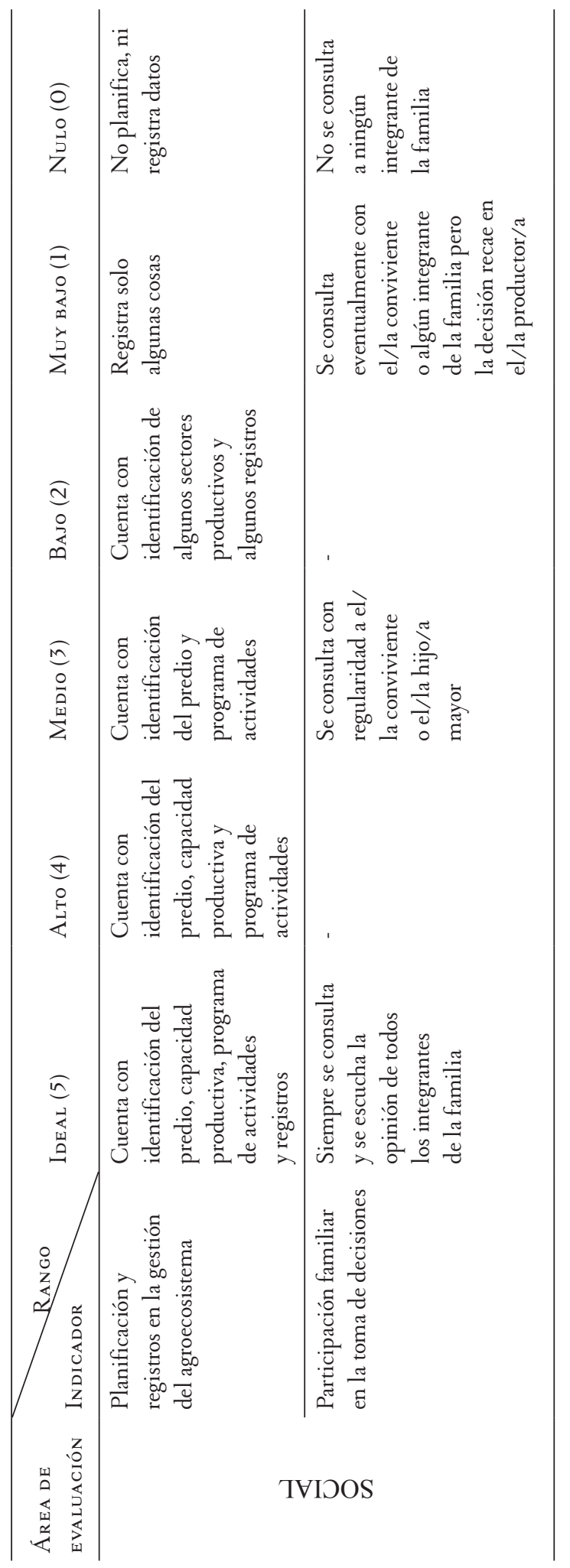




\section{Referencias}

Abbona, E. y Sarandón, S. (2014). Manejo de nutrientes en los agroecosistemas. En S. J. Sarandón (Ed.), Agroecología: bases teóricas para el diseño y manejo de agroecosistemas sustentables (pp. 2II-234). La Plata: Universidad Nacional de La Plata.

Alemany, C. y Sevilla Guzmán, E. (2007). ¿Vuelve la extensión rural? Reflexiones y propuestas agroecológicas vinculadas con el retorno y fortalecimiento de la extensión rural en América Latina. Realidad Económica, 227, 52-74.

Altieri, M. y Nicholls, C. (2000). Agroecología. Teoría y práctica para una agricultura sustentable. Distrito Federal: Programa de las Naciones Unidas para el Medio Ambiente.

Altieri, M. y Toledo, V. (20II). The agroecological revolution of Latin America: rescuing nature, securing food sovereignity and empowering peasants. Journal of Peasant Studies XX, 36, 587-612. http://dx.doi.org/10.1080/03066150.2011.582947 Apaza, D., Arroyo, R. y Alencastre, A. (2006). Las amunas de Huarochirí: Recarga de acuiferos en los Andes. Lima: Gestión social del agua y ambiente en cuencas - GSAAC.

Báez, K. (2005). Impacto de la innovación tecnológica en la sustentabilidad de los sistemas de producción de campesinos Pebuenches. Comuna de Lonquimay. IX Región de la Araucanía (tesis de pregrado). Santiago: Universidad de Chile.

Beck, J. (2013). Presionar a favor de las regiones de montaña y su agricultura. En S. Wymann von Dach, R. Romeo, A. Vita, M. Wurzinger y T. Kohler (Eds.), La Agricultura de montaña es agricultura familiar: Una contribución de las zonas de montaña al Año Internacional de la Agricultura Familiar 2014 (pp. 38-39). Roma, Italia: FAO, CDE, BOKU.

Beniston, M. (2003). Climatic Change in Mountain Regions: a Review of Possible Impacts. Climatic Change, 59, 5-3I.

Benítez, S. (2005). La artesanía latinoamericana como factor de desarrollo económico, social y cultural: a la luz de los nuevos conceptos de cultura y desarrollo. Revista Desarrollo y Cultura, 6, 3-10.

Berdegué, J. (20I4). La agricultura familiar en Chile. Serie Documentos de Trabajo $N^{\circ} 152$. Santiago, Chile: Rimisp-Grupo de Trabajo Desarrollo con Cohesión Territorial. Recuperado de http://www.rimisp.org/wp-content/files_mf/I434743401152Agricult uraFamiliarenChileversionrevisadalarga_editado.pdf Bolvito, J., Macario, T. y Sandoval, K. (2008) Conocimiento Tradicional Colectivo y Biodiversidad. Guatemala: Consejo Nacional de Áreas Protegidas. 
Borsdorf, A. (1995). Dritte Welt und Weltwirtschaft, 4. Auflage: Stuttgart.

Borsdorf, A., Stötter, J., Grabherr, G., Bender, O., Marchant, C. y Sánchez, R. (20I4) Impacts and Risks of Global Change. En Grover, V., Borsdorf, A., Breuste, J., Chandra Tiwari, P. y Witkowski Frangetto, F. (Eds.), Impacts of Global Change on Mountains: Responses and Adaptation (pp. 33-76). London: CRC Press Taylor \& Francis Goup.

Calvente, A. (2007). El concepto moderno de sustentabilidad. Centro de Altos Estudios Globales. Universidad Abierta Interamericana. Recuperado de http://www. sustentabilidad.uai.edu.ar/pdf/sde/UAIS-SDS-ı00-002\%20-\%20Sustentabilidad.pdf

Ceccon, Eliane. (2008). La revolución verde tragedia en dos actos. Ciencias, I(9I/julioseptiembre) 2I-29.

Contreras, R. (2000). Empoderamiento campesino y desarrollo local. Revista Austral de Ciencias Sociales, 4, 55-68.

Ellis, F. y Biggs, S. (200I). Evolving themes in rural development I950s-2000s. Development Policy Review, I9(4), 437-448.

FAO (1996). Enseñanzas de la Revolución Verde: hacia una nueva revolución verde. Documentos técnicos de referencia. Recuperado de http://www.fao.org/docrep/003/w26I2s/ w2612s06.htm

FAO (20I4). Acto de clausura. Año Internacional de la Agricultura Familiar. En El Legado del AIAF 2014 y el camino a seguir (pp. I-4). Filipinas: FAO.

FAO (20I3). Captación y almacenamiento de agua de lluvia: Opciones técnicas para la agricultura familiar en América Latina y el Caribe. Santiago: FAO.

FAO (2002). Alimentación familiar, alimentación a grupos y alimentos de venta callejera. En FAO (Ed.), Nutrición bumana en el mundo en desarrollo (pp. 437-462). Roma: FAO.

FAO (2002). Los fertilizantes y su uso. Dirección de Fomento de Tierras y Aguas. París: FAO. Gutiérrez, J., Aguilera, L., González, C. y Juan, J. (2012). Evaluación de la sustentabilidad posterior a una intervención agroecológica en el subtrópico del altiplano central de México. Tropical and subtropical agroecosystems, I5(I), I5-24.

Gutiérrez, J., Aguilera, L. y González, C. (2008). Agroecología y sustentabilidad. Convergencia, 15 (46), $5 \mathrm{I}-87$.

IPCC. Cambio Climático 2007. Informe de Síntesis. Recuperado de http://www.ipcc.ch/ pdf/assessment-report/ar4/syr/ar4_syr_sp.pdf, 2007.

Indap (20I4). Lineamientos estratégicos 20I4-20I8. Recuperado de http://www.indap. gob.cl/docs/default-source/default-document-library/lineamientos-estrategicos. pdf?sfvrsn=o 
Indap (2016). Norma técnica y procedimientos operáticos del programa "sello manos campesinas". Recuperado de http://www.manoscampesinas.cl/documentos/ norma-tecnica-programa-regular-sello-manos-campesinas

Infante, A. (2013). Agroecología y programas de desarrollo sustentable en el secano de Chile. En Nicholls, C., Ríos, L. y Altieri, M. (Eds.), Agroecología y resiliencia socioecológica: adaptándose al cambio climático (pp. I-17). Medellín: Cyted.

Inostroza, J. (2009). Manual de Papas en La Araucanía: Manejo y Plantación. Vilcun: Instituto de Investigaciones Agropecuarias, Centro Regional Carillanca.

Kohler, T. y Romeo, R. (20I3). La agricultura de montaña es agricultura familiar. En S. Wymann von Dach, R., Romeo, A. Vita, M. Wurzinger, y T., Kohler, La Agricultura de montaña es agricultura familiar: Una contribución de las zonas de montaña al Año Internacional de la Agricultura Familiar 2014 (pp. Iо-II). Roma: FAO, CDE, BOKU.

La Vía Campesina (2013). Informe Anual 2013. Agricultura campesina sostenible: nuestro derecho a la vida (pp 9-I2).

Leff, E. (2000). Tiempo de sustentabilidad. Ambiente E- Sociedade, III(6-7), 5-13.

Marchant, C. y Sánchez, R. (20II). Challenges and opportunities for the sustainability of mountain municipalities in Chile. En Borsdorf, A, Stötter, J. y Veulliet, E. (Eds.), Managing Alpine Future II. Inspire and drive sustainable mountain regions. Proceedings of the Innsbruck Conference (pp. 85-93). Vienna: Austrian Academy of Science.

Martínez, M. E. y Rosset, P. (20I2). Del conflicto de modelos para el mundo rural emerge la vía campesina como movimiento social transnacional. Luchas Agrarias en América Latina, 2I-57. Recuperado de http://www.landaction.org/IMG//pdf/ Articulo_Del_conflicto_de_modelos.pdf

Masera, O., Astier, M. y López-Ridaura, S. (I999). Sustentabilidad y manejo de recursos naturales: El marco de evaluación MESMIS. México D.F.: Mundi-Prensa.

Ministerio de Desarrollo Social. (2015). Informe de Desarrollo Social 2015. Santiago: Gobierno de Chile.

Montaña, E. (20I3). Escenarios de cambio ambiental global, escenarios de pobreza rural. Buenos Aires: Clacso.

Nazif, I. (2009). Institucionalidad para el desarrollo de la agricultura familiar campesina. Santiago: Odepa.

Odepa (2012). Comercialización de productos hortifruticolas en la pequeña agricultura. Santiago de Chile: Odepa.

Olivares, P., Smith-Ramírez, C., Zenteno, V. y Fernández, X. (2009). Manual Diseño de Planes Integrales Prediales. Puerto Montt: Biodiversa. 
Ortiz, T. y Astier, M. (2003). Sistematización de experiencias agroecológicas en Latinoamérica. LEISA Revista de Agroecología, 4-6.

Pacheco, G., Henríquez, C., Sampaio, C. y Oyarzún, E. (20II). Encadenamientos socioproductivos y ecosocioeconomia de las organizaciones. Análisis propositivo para el Turismo de Intereses Especiales (TIE) en el territorio lacustre de la región de la Araucanía. Gestión Turística, I6, 49-68.

Peredo, S. y Barrera, C. (2002). Transformaciones socioculturales y ambientales en la comunidad rural mapuche "Estaban Loncomil" en el Sector Maquehue, Chile: los efectos invisibles de una modernización convencional. IX congreso de Antropología. Simposio recreaciones medioambientales, políticas de desarrollo y turismo (pp. I-I6). Barcelona: Universidad de Córdoba.

Pérez, D. y Montiel, M. (2013). Agroecología y ecofeminismo para descolonizar y despatriarcar la alimentación globalizada. Revista Internacional de pensamiento político, $8,95-$ III.

Pérez Nieto, J., Valdés Velarde, E., y Ordaz Chaparro, V. M. (2012). Cobertura vegetal y erosión del suelo en sistemas agroforestales de café bajo sombra. Terra Latinoamericana, 30(3), 249-259.

Petersen, P. (2003). Evaluando la sustentabilidad: estudios de caso sobre impactos de innovaciones agroecológicas en la agricultura familiar de diferentes países latinoamericanos. LEISA Revista de Agroecología, Io(o), 64-67.

Prieto, J. (2002). La agricultura y la ganadería en zonas de montaña para el siglo XXI. Actas del XV SICODER (pp. 79-92). Zaragoza, España.

Qualitas (2009). Estudio de caracterización de los hogares de las explotaciones silvoagropecuarias a partir del VII Censo Nacional Agropecuario y Forestal. Santiago.

Red Reserva Biosfera Araucarias (20I0). Reserva Biosfera Araucarias. Recuperado de http://rbaraucarias.cl/rbaraucarias/

Rosset, P., Collins, J., y Moore, F. (2000). Lessons the Green Revolution: Do We Need New Technology to End Hunder? Tikkun Magazine, 8(2) 52-56.

Ruiz, N. y Delgado, J. (2008). Territorio y nuevas ruralidades: un recorrido teórico sobre las transformaciones de la relación campo-ciudad. EURE, 34(102), 77-95.

Sepúlveda, S., Rodríguez, A., Echeverri, R. y Portilla, M. (2003). El enfoque territorial del desarrollo rural. San José, Costa Rica: IICA.

Sevilla, E., y Soler, M. (2009). Del desarrollo rural a la agroecología (monografía). Documentación Social, 155 (pp. 25-4I). 
Schneider, S. (2009). La pluriactividad en el medio rural brasileño. En de Grammont, H.C, y L., Martínez (Eds.), La pluriactivdad en el campo latinoamericano (pp. 207-242). Quito: Flacso.

Szmulewicz, P.; Gutiérrez, C. y Winkler, K. (20I2). Evaluación de las habilidades asociativas en redes de agroturismo del sur de Chile. Estudios y Perspectivas en Turismo, 2I, I0I3-1034.

Singh, V. (2004). La diversidad en la agricultura de montaña. Recuperado de http:// www.agriculturesnetwork.org/magazines/latin-america/montanas-en-equilibrio/ la-diversidad-en-la-agricultura-de-montana

Tommasino, H. y Hegedüs, P. (2006). Sustentabilidad Rural: Desacuerdos y Controversias. En Extensión: reflexiones para la intervención en el medio urbano y rural (pp 79-98). Montevideo: Udelar / Fagro.

Torres, J., Frías, C. y de la Torre, C. (2014). Adaptación en ecosistemas de montaña (ELLA). Lima: Soluciones Prácticas.

Vargas, R., Castro, A. y Ziadat, F. (2015). Mountain soils and ecosystem services. En FAO, Understanding mountain soils (pp. 7-9). Roma: FAO.

Wezel, A., Bellon, S., Doré, T., Francis, C., Vallod, D. y David, C. (2009).

Agroecology as a science, a movement and a practice. A review. Agronomy for

Sustainable Development, 29, 503-515.

World Commision on Environment and Development (WCED) (1987). Our Common Future. Brundtlland Report. United Nations.

Wymann von Dach, S., Romeo, R., Vita, A., Wurzinger, M. y Kohler, T. (2013). La Agricultura de montaña es agricultura familiar: Una contribución de las zonas de montaña al Año Internacional de la Agricultura Familiar 2014. Roma, Italia: FAO, CDE, BOKU. 